\title{
Novos aditivos microbianos na ensilagem da cana-de-açúcar: composição bromatológica, perdas fermentativas, componentes voláteis e estabilidade aeróbia
}

\author{
Patrick Schmidt ${ }^{1}$, Paulo Rossi Junior ${ }^{1}$, Daniel Junges ${ }^{2}$, Laila Talarico Dias ${ }^{1}$, Rodrigo de \\ Almeida $^{1}$, Lucas José Mari ${ }^{3}$
}

\footnotetext{
${ }^{1}$ Departamento de Zootecnia da Universidade Federal do Paraná, Curitiba, PR.

2 Programa de Pós-graduação em Ciências Veterinárias na Universidade Federal do Paraná, Curitiba, PR.

${ }^{3}$ Médico Veterinário, Piracicaba, SP.
}

RESUMO - Nesta pesquisa, comparou-se a inclusão de aditivo composto por cepas de Lactobacillus brevis + Enterococcus faecium + L. plantarum à inoculação com aditivo comercial contendo cepas de Lactobacillus buchneri e à ensilagem sem aditivos (controle). As silagens foram confeccionadas em silos experimentais e armazenadas por 90 dias antes da abertura do silo. Foram avaliadas a composição bromatológica da cana-de-açúcar antes e após a ensilagem, a composição de ácidos orgânicos e etanol das silagens, a estabilidade aeróbia e as perdas fermentativas durante o processo de ensilagem. O uso do aditivo composto e do aditivo comercial contendo cepas de Lactobacillus buchneri provocou aumento da produção de efluentes e de gases e da perda total de matéria seca. O teor de ácido lático da silagem aumentou com o uso do aditivo composto, embora esse aditivo também tenha elevado o teor de etanol (18,6\% da MS) em relação ao da silagem controle $(14,4 \%)$. A estabilidade aeróbia da silagem não foi influenciada pelos inoculantes adicionados no processo de ensilagem. Os aditivos aplicados prejudicaram o processo de ensilagem da cana-de-açúcar.

Palavras-chave: etanol, gases, Lactobacillus brevis, Lactobacillus buchneri, silagem

\section{New microbial additives on sugarcane ensilage: bromatological composition, fermentative losses, volatile compounds and aerobic stability}

\begin{abstract}
In this study, the inclusion of Lactobacillus brevis + Enterococcus faecium + L. plantarum was compared to the inoculation with a commercial additive containing strains of Lactobacillus buchneri and to the silage without additives (control). Silages were prepared in experimental silos and stored for 90 days before opening of the silos. It was evaluated chemical composition of sugarcane before and after ensiling process, composition of organic acids and ethanol in the silages, aerobic stability and fermentative losses during the ensiling process. Use of compound additive and commercial additive containing strains of Lactobacillus buchneri increased production of effluents and gas and total dry matter losses. Lactic acid content in the silage increased with the use of compound additive, although this additive had increased content of ethanol (18.6\% of DM) compared with the control ensilage (14.4\%). Aerobic stability in the silage was not influenced by inoculants added into ensilage process. The additives used have impaired the ensiling process of sugarcane.
\end{abstract}

Key Words: ethanol, gases, Lactobacillus brevis, Lactobacillus buchneri, silage

\section{Introdução}

A ensilagem da cana-de-açúcar (Saccharum officinarum L.) é uma alternativa para conservação dessa forragem visando à otimização de atividades no canavial e facilidade operacional. Assim, a aplicação dessa técnica tem aumentado nos últimos anos e constitui uma opção interessante para os demais volumosos suplementares.

Como as perdas de matéria seca (MS) durante o processo fermentativo das silagens de cana-de-açúcar são elevadas, o uso de aditivos é importante para reduzir a intensidade da fermentação alcoólica, típica desse material (Schmidt, 2009). A escolha de um aditivo para ensilagem deve ser baseada em aspectos como: recuperação de MS, estabilidade após abertura dos silos e relação custo e beneficio da aplicação, uma vez que, em poucos casos, o desempenho dos animais é influenciado pela aplicação de aditivos na ensilagem (Kung \& Muck, 1997).

Têm-se observado efeitos deletérios de aditivos microbianos contendo bactérias homofermentativas 
produtoras de ácido lático, como Lactobacillus plantarum e Enterococcus faecium, em silagens de cana-de-açúcar, provavelmente em decorrência do metabolismo do ácido lático produzido por esses microrganismos em fermentações secundárias mediadas por leveduras (Danner et al., 2003). Em contrapartida, as bactérias heteroláticas produtoras de ácidos acético e propiônico, além do ácido lático, como L. brevis e L. buchneri, parecem promover certa inibição no crescimento de leveduras nas silagens de cana (Pedroso et al., 2007; Siqueira et al., 2007), embora exista grande variabilidade nos resultados de pesquisas disponíveis até o momento. Schmidt (2009) observou grande variação nos resultados experimentais em pesquisa com o uso de aditivos na ensilagem da cana-de-açúcar, provavelmente em decorrência da variação na população da microbiota epifítica da forragem usada na confecção das silagens. Análise conjunta de dezenas de ensaios com aditivos microbianos comprovou de forma marcante resultados diferentes para a ação de bactérias homo ou heteroláticas quando aplicadas à cana durante a ensilagem. Contudo, as razões para resultados divergentes usando as mesmas espécies de microrganismos ainda permanecem desconhecidas.

A busca por novos aditivos ou por combinações de produtos que apresentem efeito sinérgico na prevenção de perdas durante a ensilagem de cana-de-açúcar mantém-se em destaque entre as pesquisas sobre forragens conservadas no Brasil, com intuito de elevar o número de informações que esclareçam a dinâmica fermentativa desse material. Nesta pesquisa, avaliaram-se as perdas fermentativas, a composição químico-bromatológica e a estabilidade aeróbia de silagens de cana-de-açúcar contendo novos aditivos à base de bactérias homo e heteroláticas em comparação a uma silagem controle, sem inoculantes.

\section{Material e Métodos}

O experimento foi realizado em uma propriedade rural no município de Santo Antônio da Platina, estado do Paraná, e a coleta e análise de dados no Departamento de Zootecnia, Setor de Ciências Agrárias da Universidade Federal do
Paraná (UFPR), em Curitiba, Paraná. A cana-de-açúcar utilizada foi da variedade RB 72-474, colhida no dia 23 de outubro de 2008, em bom estádio de maturação (média de 22,7 Brix).

O material foi colhido utilizando-se ensiladeira acoplada a um trator e foi picado em partículas de $10 \mathrm{~mm}$, aproximadamente. Foram testados dois aditivos, um comercial, contendo Lactobacillus buchneri $\left(5 \times 10^{4} \mathrm{ufc} / \mathrm{g}\right)$, e outro composto de cepas de L. brevis + Enterococcus faecium + L. plantarum $\left(1 \times 10^{5} \mathrm{ufc} / \mathrm{g}\right)$, avaliados em comparação a uma silagem controle, sem aditivos.

O aditivo Lactobacillus buchneri foi aplicado na dosagem de aditivo recomendada pelo fabricante (2 g/t de forragem fresca), enquanto o aditivo $L$. brevis + Enterococcus faecium + L. plantarum foi usado na dosagem de $4 \mathrm{~g} / \mathrm{t}$ de forragem fresca. Os inoculantes foram diluídos em água destilada (1 L/t) e pulverizados uniformemente na forragem fresca, imediatamente antes do enchimento dos silos. A compactação foi realizada com os pés, buscando-se massa específica de $600 \mathrm{~kg} / \mathrm{m}^{3}$.

Como silos experimentais foram usados baldes plásticos de $20 \mathrm{~L}$ equipados de aparato para determinação de perdas, conforme metodologia descrita por Jobim et al. (2007), usando-se cinco repetições por tratamento e considerando cada silo uma unidade experimental. Os silos foram pesados antes (vazios) e após o enchimento e, em seguida, foram vedados com fita adesiva e armazenados em temperatura ambiente, em galpão coberto, por 90 dias.

No momento da ensilagem, foi coletada uma amostra de cada silagem para determinação do teor de matéria seca (MS) e da composição bromatológica (Tabela 1).

Após o período de armazenagem, cada silo foi novamente pesado e a silagem retirada e homogeneizada em sacos plásticos. De cada silo foram retiradas três amostras para análises químicas e bromatológicas, e a massa restante foi usada para o ensaio de estabilidade aeróbia das silagens. Uma amostra foi seca em estufa de ventilação forçada a $55^{\circ} \mathrm{C}$, durante 72 horas, e processada em moinho estacionário tipo Wiley, utilizando peneira com crivos de $1 \mathrm{~mm}$. Outras duas alíquotas foram mantidas congeladas para posterior determinação do $\mathrm{pH}$, em

Tabela 1 - Composição bromatológica da cana-de-açúcar no momento da ensilagem

\begin{tabular}{|c|c|c|c|c|}
\hline \multirow[b]{2}{*}{ Variável } & \multicolumn{3}{|c|}{ Silagem } & \multirow[b]{2}{*}{ Média } \\
\hline & Controle & L. buchneri $\left(5 \times 10^{4} \mathrm{ufc} / \mathrm{g}\right)$ & $\begin{array}{l}\text { L. brevis }+ \text { Enterococcus faecium }+ \\
\text { L. plantarum }\left(1 \times 10^{5} \mathrm{ufc} / \mathrm{g}\right)\end{array}$ & \\
\hline Matéria seca, \% & 32,5 & 34,2 & 32,6 & 33,1 \\
\hline Proteína bruta, \% da MS & 1,90 & 1,82 & 1,76 & 1,83 \\
\hline Fibra em detergente neutro, \% da MS & 49,5 & 52,3 & 49,7 & 50,5 \\
\hline Fibra em detergente ácido, \% da MS & 31,4 & 32,8 & 32,2 & 32,1 \\
\hline
\end{tabular}


extrato aquoso, e dos compostos voláteis, em suco prensado da silagem.

As análises bromatológicas foram realizadas no Laboratório de Nutrição Animal do Departamento de Zootecnia da Universidade Federal do Paraná (DZ/UFPR). Os teores de MS e Proteína Bruta (PB) foram determinados segundo metodologia descrita por Silva \& Queiroz (2002) e os teores de fibra em detergente neutro (FDN) e fibra em detergente ácido (FDA) foram avaliados pelo método sequencial, conforme técnicas descritas por Van Soest et al. (1991). Para confeç̧ão do extrato aquoso, $25 \mathrm{~g}$ de silagem foram adicionados a $225 \mathrm{~mL}$ de água deionizada e o $\mathrm{pH}$ no extrato foi determinado em potenciômetro digital modelo WTW 330i.

As análises de ácidos orgânicos (ácidos lático, acético, propiônico e butírico) e etanol foram realizadas por cromatografia gasosa no Laboratório de Bromatologia da Faculdade de Medicina Veterinária e Zootecnia da Universidade de São Paulo (FMVZ/USP), em Pirassununga, São Paulo.

A perda de matéria seca na forma de gases foi calculada pela diferença entre o peso da matéria seca inicial e final nos silos experimentais e a quantidade de efluentes, pela diferença entre os pesos inicial e final dos silos contendo areia, tela plástica e tecido de algodão, conforme descrito por Jobim et al. (2007). A perda total de matéria seca foi calculada pela diferença entre o peso da matéria seca da forragem inicialmente colocada em cada silo experimental e o peso da matéria seca da silagem recuperada no dia da abertura, descontando-se o efluente produzido.

A estabilidade aeróbia das silagens foi avaliada por meio da temperatura das silagens expostas ao ar, de acordo com o método descrito por Kung et al. (2000). Amostras de 3,0 kg de cada unidade experimental foram colocadas em baldes plásticos sem tampa, que foram mantidos em câmara climática a $25 \pm 1^{\circ} \mathrm{C}$ durante dez dias. As temperaturas foram mensuradas a cada 30 minutos com o uso de dataloggers (EL-USB-1 - Lascar Eletronics/U.K.), inseridos no centro da massa em cada balde. Amostras das silagens foram colhidas ao início e término do período de avaliação, para determinação do teor de MS em estufa de circulação forçada de ar a $55^{\circ} \mathrm{C}$.

As variáveis avaliadas foram: estabilidade aeróbia, definida como o tempo em horas para elevação da temperatura em $2^{\circ} \mathrm{C}$ em relação ao ambiente; temperatura máxima alcançada pela massa, em graus celsius; tempo, em horas, para atingir a temperatura máxima; perda de matéria seca, de zero a dez dias.

Em todas as avaliações, usou-se o delineamento experimental inteiramente casualizado, com três silagens (controle, L. buchneri e L. brevis + Enterococcus faecium + L. plantarum), cada uma com cinco repetições. Os resultados foram submetidos à análise de variância, e as comparações entre as médias foram realizadas pelo teste Tukey considerando o nível de 5\% de probabilidade de erro, mediante PROC GLM (SAS, 1996).

\section{Resultados e Discussão}

Os teores de matéria seca da forragem reduziram de $33,1 \%$ na ensilagem (Tabela 1 ) para 28,6\% na média das três silagens após 90 dias de conservação. Houve significativa diminuição do teor de MS para a silagem $L$. brevis + Enterococcus faecium $+L$. plantarum, e isso indica desaparecimento de MS decorrente do processo fermentativo, provavelmente pela maior atividade da população de leveduras durante a ensilagem. Esses microrganismos são responsáveis pelo consumo de açúcares no processo, liberando dióxido de carbono $\left(\mathrm{CO}_{2}\right)$ resultante de seu metabolismo (Moon, 1983; McDonald et al., 1991). Em condições anaeróbias, leveduras obtêm energia da fermentação de açúcares, produzindo 2 moles de $\mathrm{CO}_{2}$ para cada mol de glicose fermentado até etanol (McDonald et al., 1991). Nesse caso, a maior perda fermentativa verificada com a inoculação de L. brevis + Enterococcus faecium + L. plantarum proporcionou maior redução no teor de MS da silagem.

Embora todas as silagens tenham sido preparadas simultaneamente e com a mesma forragem, falhas de amostragem podem ter refletido em teores de componentes fibrosos ligeiramente maiores na forragem usada em L. buchneri (Tabela 1). Os teores de FDN e FDA nessas silagens não foram influenciados pelos aditivos, pois foram semelhantes. Contudo, verificou-se elevação média de 17,8 e 12,7 unidades percentuais nos teores de FDN e FDA, respectivamente, da cana-de-açúcar antes e após a ensilagem. De acordo com Pedroso et al. (2007), com o passar do tempo, os componentes fibrosos tornam-se mais concentrados na MS da silagem, em razão da perda de carboidratos solúveis na forma de gases e efluentes durante a ensilagem.

Os valores de FDN e FDA observados nas silagens foram superiores aos encontrados na maior parte dos trabalhos publicados (Pedroso et al., 2005; Amaral et al., 2009; Valeriano et al., 2009), provavelmente em virtude das altas perdas fermentativas (Tabela 2) e da produção de etanol (Tabela 3) verificadas nesta pesquisa.

O teor proteico da silagem inoculada com L. buchneri foi superior ao da silagem controle, todavia, a fração proteica 
Tabela 2 - Perdas fermentativas e variáveis bromatológicas nas silagens de cana-de-açúcar

\begin{tabular}{lcccc}
\hline & \multicolumn{3}{c}{ Silagem } \\
\cline { 2 - 4 } Variável & $\begin{array}{c}\text { Controle, } \\
\text { sem aditivos }\end{array}$ & L. buchneri & L. brevis $+\begin{array}{c}\text { Enterococcus faecium }+ \\
\text { L. plantarum }\end{array}$ & Média \\
\hline Matéria seca, \% & $29,5 \mathrm{a}$ & $29,3 \mathrm{a}$ & $26,8 \mathrm{~b}$ & 28,6 \\
Proteína bruta, \% da MS & $2,10 \mathrm{~b}$ & $2,33 \mathrm{a}$ & $2,25 \mathrm{ab}$ & 2,73 \\
Fibra em detergente neutro, \% da MS & 69,5 & 67,5 & 67,8 & 4,93 \\
Fibra em detergente ácido, \% da MS & 46,2 & 44,6 & 43,5 & 3,11 \\
pH & $3,62 \mathrm{a}$ & $3,61 \mathrm{a}$ & $3,50 \mathrm{~b}$ & 4,3 \\
Efluentes, kg/t & $5,4 \mathrm{~b}$ & $5,8 \mathrm{~b}$ & $18,2 \mathrm{a}$ & 3,58 \\
Gases, \% da MS & $13,9 \mathrm{c}$ & $20,8 \mathrm{~b}$ & $25,7 \mathrm{a}$ & 9,35 \\
Perda total MS, \% & $14,4 \mathrm{c}$ & $21,3 \mathrm{~b}$ & $27,2 \mathrm{a}$ & 20,6 \\
\hline
\end{tabular}

Médias seguidas por letras diferentes na linha são estatisticamente diferentes $(\mathrm{P}<0,05)$ pelo teste Tukey.

da cana é bastante limitada e a elevação nos teores proteicos das silagens em relação ao material original decorre das perdas de MS observadas nessas silagens. Valeriano et al. (2009) afirmaram que a rápida queda no $\mathrm{pH}$ das silagens de cana impede o crescimento de microrganismos que degradam proteínas, como enterobacterias e clostrídeos, o que explica a não-redução nos teores de PB dessas silagens.

A silagem inoculada com o composto de L. brevis + Enterococcus faecium $+L$. plantarum apresentou o mais baixo $\mathrm{pH}$ e isso indica maior desenvolvimento de bactérias láticas e maior produção de ácido lático (Tabela 3). Contudo, essa redução do pH não foi suficiente para reduzir as perdas fermentativas de MS. Esses dados corroboram as afirmações de que o ácido lático não é bom inibidor da atividade de leveduras e serve ainda como substrato ao seu metabolismo. McDonald et al. (1991) afirmaram que, em condições de anaerobiose, as leveduras podem se desenvolver em $\mathrm{pH}$ inferior a 2, desde que haja disponibilidade de carboidratos solúveis no meio. $\mathrm{O}$ pH foi baixo em todas as silagens, e não constitui bom indicativo de qualidade fermentativa em silagens de cana (Schmidt et al., 2007).

A produção de efluentes foi maior na silagem tratada com o composto de inoculantes, provavelmente em decorrência da maior perda de MS e da consequente elevação no teor de umidade dessa silagem. Assim, os valores encontrados nesse ensaio podem ser considerados baixos, se comparados aos citados na literatura para silagens de cana-de-açúcar inoculadas com aditivos microbianos, que variam de 22,8 (Pedroso et al., 2007) a 84,9 kg/t de forragem fresca (Siqueira et al., 2007).

Os aditivos testados foram ineficientes em prevenir as perdas fermentativas e, pelo contrário, provaram elevações de 47,9 e 88,9\% nas perdas totais de MS, em decorrência da inoculação com L.buchneri e com L. brevis + Enterococcus faecium + L. plantarum, respectivamente. Em média, as perdas de MS na forma de gases responderam por $96 \%$ das perdas totais de MS e são a principal via de perdas fermentativas em silagens de cana-de-açúcar (Santos et al., 2008; Baliero Neto et al., 2009).

As silagens de cana-de-açúcar que produzem grande quantidade de gases apresentam maior teor de etanol, maior perda total de MS e, consequentemente, menor valor nutritivo (Pedroso et al., 2007), em decorrência do desaparecimento de compostos solúveis de alta digestibilidade, como a sacarose. Esse efeito é verificado na maior parte dos trabalhos publicados, em que a produção de etanol não foi eficientemente controlada pelos aditivos testados.

A maior perda fermentativa de MS na silagem inoculada com o aditivo composto, contendo microrganismos homoláticos está de acordo com observações de Schmidt (2009) de que, em 91\% dos trabalhos publicados sobre avaliação da espécie L . plantarum em silagens de cana-deaçúcar, as perdas fermentativas foram iguais ou superiores às da silagem sem aditivos. Para as silagens inoculadas com L. buchneri, o autor verificou $44 \%$ de resultados positivos para diminuição das perdas de MS na ensilagem da cana.

Segundo McDonald et al. (1991), o metabolismo das bactérias homoláticas é acelerado em relação às heteroláticas, prevalecendo a fermentação lática sobre os microrganismos heterofermentativos. Neste ensaio, na associação do $L$. plantarum e E. faecium com o L. brevis, prevaleceu a fermentação lática, confirmada pela maior quantidade do ácido lático produzido, possivelmente usado no metabolismo das leveduras, elevando a produção de etanol (Tabela 3).

Os teores dos ácidos acético, propiônico e butírico não diferiram entre as silagens, com teores médios de 2,85; 0,03 e 0,06\% da MS, respectivamente (Tabela 3). Esses valores estão bem próximos aos valores médios observados por Schmidt et al. (2007), que verificaram teores de 2,31; 0,21 e 0,05\% da MS para os ácidos acético, propiônico e butírico, respectivamente. A inoculação com $L$. buchneri não foi 
efetiva em aumentar a produção de ácido acético das silagens, conforme observado por outros autores (Freitas et al., 2006; Sousa et al., 2008). Esses resultados também diferem dos valores compilados por Kleinschmit \& Kung (2006), que observaram elevação média de 1,7 unidades percentuais no teor de ácido acético em silagens de milho inoculadas com esse aditivo.

O teor de ácido lático das silagens foi maior na silagem inoculada com L . brevis + Enterococcus faecium $+L$. plantarum e essa diferença confirma a fermentação preferencial realizada por bactérias homoláticas, o que reduziu o $\mathrm{pH}$ da silagem tratada com o composto de inoculantes, sem, contudo, reduzir a fermentação alcoólica nesse material. O valor observado (4,34\% da MS) é inferior aos relatados por Muñoz-Maldonado (2007), de 5,02\% da MS, e por Freitas et al. (2006), de 5,30\% da MS, em silagens de cana inoculadas com $L$. plantarum. Ressalta-se que o teor de ácido lático obtido nas silagens não representa necessariamente a quantidade desse ácido produzido no processo fermentativo, uma vez que parte dele pode ser metabolizada a etanol pelas leveduras presentes na silagem (Moon, 1983), embora esse processo ocorra mais frequentemente sob aerobiose (McDonald et al., 1991). O teor de etanol nessa silagem, tratada com o composto de inoculantes, também foi maior e esse resultado confirma a hipótese de menor controle da fermentação alcoólica pelo ácido lático produzido por microrganismos homoláticos inoculados nas silagens de cana (Moon, 1983), uma vez que a associação com bactérias heteroláticas, nesse caso, não foi efetiva em reverter esse efeito.

Os teores de etanol verificados em todas as silagens, apesar de bastante elevados, são condizentes com as perdas fermentativas de MS e com o maior teor de ácido lático da silagem inoculada com o composto de inoculantes. Freitas et al. (2006) relataram teor de etanol de $18,2 \%$ da MS para silagens de cana inoculadas com L. plantarum, o qual resultou em perda fermentativa de 30,6\% da MS. Os dados desta pesquisa corroboram a afirmativa de que adição de bactérias homoláticas na ensilagem da cana-de-açúcar é prejudicial ao processo (Schmidt, 2009). O etanol produzido na silagem de cana-de-açúcar sem aditivo $(14,4 \%)$ foi próximo aos obtidos por Kung \& Stanley (1982) e Freitas et al. (2006) (17,8\% e 15,5\%), porém muito superior aos relatados por Pedroso et al. (2007) e Sousa et al. (2008), de 3,82 e 8,27\% da MS, respectivamente. Provavelmente, a grande variação nas perdas fermentativas e na composição em ácidos orgânicos e etanol entre experimentos seja devida às diferenças na população de microrganismos epifíticos presentes no material ensilado (Pedroso et al., 2005). Contudo, são raros os trabalhos publicados na literatura e que incluem essa variável.

Nenhuma das variáveis avaliadas no período de dez dias foi influenciada pelos aditivos aplicados nas silagens durante a fase de exposição aeróbia (Tabela 4). Em parte, a ausência de aumento nos teores dos ácidos controladores da degradação aeróbia (acético, propiônico e butírico) nas silagens inoculadas (Tabela 3) pode explicar a resposta

Tabela 3 - Composição dos ácidos orgânicos e etanol nas silagens de cana-de-açúcar

\begin{tabular}{|c|c|c|c|c|c|}
\hline \multirow[b]{2}{*}{ Variável } & \multicolumn{3}{|c|}{ Silagem } & \multirow[b]{2}{*}{ Média } & \multirow[b]{2}{*}{ CV $(\%$} \\
\hline & $\begin{array}{l}\text { Controle, } \\
\text { sem aditivos }\end{array}$ & L. buchneri & $\begin{array}{c}\text { L. brevis }+ \text { Enterococcus faecium }+ \\
\text { L. plantarum }\end{array}$ & & \\
\hline Ácido acético, \% da MS & 2,85 & 2,78 & 2,93 & 2,85 & 16,5 \\
\hline Ácido propiônico,\% da MS & 0,04 & 0,03 & 0,03 & 0,03 & 40,3 \\
\hline Ácido butírico,\% da MS & 0,06 & 0,07 & 0,06 & 0,06 & 48,3 \\
\hline
\end{tabular}

Médias seguidas por letras diferentes, na linha, são estatisticamente diferentes $(\mathrm{P}<0,05)$ pelo teste Tukey.

Tabela 4 - Estabilidade aeróbia de silagens de cana-de-açúcar tratadas com bactérias homo e heterofermentativas

\begin{tabular}{lcccc}
\hline & \multicolumn{3}{c}{ Silagem } \\
\cline { 2 - 4 } Variável & $\begin{array}{c}\text { Controle, } \\
\text { sem aditivos }\end{array}$ & L. buchneri & $\begin{array}{c}\text { L. brevis }+ \text { Enterococcus faecium }+ \\
\text { L. plantarum }\end{array}$ & Média \\
CV (\%) \\
Estabilidade aeróbia, horas ${ }^{1}$ & 34,7 & 40,8 & 41,4 & 38,9 \\
Temperatura máxima atingida, ${ }^{\circ} \mathrm{C}$ & 46,5 & 45,1 & 45,8 & 18,30 \\
Tempo para atingir a temperatura máxima, horas & 48,2 & 65,1 & 53,2 & 2,04 \\
Perda de matéria seca, \%MS & 6,70 & 9,37 & 9,61 & 25,37 \\
\hline
\end{tabular}

Médias seguidas por letras diferentes na linha são estatisticamente diferentes $(\mathrm{P}<0,05)$ pelo teste Tukey.

${ }^{1}$ Horas para elevação da temperatura em $2^{\circ} \mathrm{C}$; PMS - perda de matéria seca de 0 a 10 dias. 
obtida após a abertura dos silos. A estabilidade aeróbia, definida como o tempo, em horas, para elevação da temperatura em $2^{\circ} \mathrm{C}$ foi numericamente maior nas silagens aditivadas, embora as perdas de MS também tenham sido numericamente superiores. Resultados de estabilidade observados por Siqueira et al. (2007) utilizando mesma dose de L. buchneri aplicada nesta pesquisa comprovam elevação na estabilidade aeróbia, de 32 para 60 horas, em relação à silagem controle. Contudo, esses autores não avaliaram o teor de ácidos graxos voláteis nas silagens.

Todas as silagens apresentaram temperatura máxima semelhante, atingindo em média $45,8^{\circ} \mathrm{C}$. Houve tendência $(\mathrm{P}=0,10)$ de aumento no tempo para se atingir temperatura máxima para a silagem inoculada com $L$. buchneri, que demorou 16,9 horas a mais para atingir o pico de temperatura após a exposição aeróbia em relação à silagem controle. Esse resultado está de acordo com o obtido por Toledo Filho et al. (2004), que observaram melhor controle na elevação da temperatura com uso desse inoculante nas silagens.

A perda de matéria seca observada entre o primeiro e o décimo dia de exposição aeróbia também não foi influenciada, embora numericamente as silagens aditivadas tenham apresentado maiores perdas. Esses resultados mostram valores concordantes com a literatura. Queiroz et al. (2006) verificaram perdas de MS de 11,8 e 15,6\%, respectivamente, em uma silagem controle e em outra com L. buchneri após 10 dias de exposição aeróbia. Siqueira et al. (2007) observaram perdas de 3,8 e 7,3\% da MS, para silagens controle e L. buchneri após cinco dias de exposição aeróbia.

As perdas de MS na fase aeróbia são decorrentes da respiração de microrganismos espoliadores, que convertem carboidratos solúveis e ácidos orgânicos em calor, água e $\mathrm{CO}_{2}$. Os resultados obtidos para essa variável, embora nãosignificativos, são conflitantes com os maiores valores de estabilidade aeróbia, sugerindo uma gama de fatores que incidem sobre a estabilidade da silagem no pós-abertura dos silos.

A grande variabilidade dos resultados de experimentos que avaliaram inoculantes microbianos em silagens comprova a necessidade de novas pesquisas na área para a busca de resultados que, avaliados em conjunto, permitam a obtenção de dados conclusivos sobre a conservação de silagens de cana-de-açúcar. Os valores de estabilidade aeróbia obtidos no ensaio indicam que silagens de cana são volumosos instáveis e susceptíveis à deterioração aeróbica após a abertura dos silos. Kleinschmit \& Kung (2006) relataram estabilidade de 206 e 245 horas, para silagens de milho controle e inoculadas com $L$. buchneri, na média de seis ensaios experimentais.
Após avaliação conjunta dos dados de perdas fermentativas, composição de ácidos orgânicos, etanol e estabilidade aeróbia, é possível afirmar que a inoculação da cana-de-açúcar com o aditivo composto de L. brevis + Enterococcus faecium + L. plantarum foi prejudicial ao processo, provavelmente em razão da predominância da fermentação homolática sobre a heterolática, na combinação das cepas bacterianas utilizadas, e comprovam a ineficácia da inoculação de silagens de cana-de-açúcar com Lactobacillus plantarum.

\section{Conclusões}

A ensilagem de cana acarreta redução na qualidade em relação à cana fresca, em virtude das perdas fermentativas que ocorrem no processo. Os aditivos microbianos testados foram ineficientes em promover alteração na rota fermentativa etanólica e reduzir as perdas no processo, ocasionando elevação na produção de gases e nas perdas totais de matéria seca. Os aditivos contendo bactérias heteroláticas não minimizaram o aquecimento e as perdas em aerobiose, demonstrando que silagens de cana-de-açúcar são volumosos instáveis e susceptíveis a degradação após a abertura dos silos.

\section{Referências}

AMARAL, R.C.; PIRES, A.V.; SUSIN, I. et al. Cana-de-açúcar ensilada com ou sem aditivos químicos: fermentação e composição química. Revista Brasileira de Zootecnia, v.38, n.8, p.1413-1421, 2009.

BALIERO NETO, G.; SIQUEIRA, G.R.; NOGUEIRA, J.R. et al. Perdas fermentativas e estabilidade aeróbia de silagens de canade-açúcar aditivadas com cal virgem. Revista Brasileira de Saúde e Produção Animal, v.10, n.1, p.24-33, 2009.

DANNER, H.; HOLZER, M.; MAYRHUBER, E. et al. Acetic acid increases stability of silage under aerobic conditions. Applied and Environmental Microbiology, v.69, n.1, p.562-567, 2003.

FREITAS, A.W.P.F.; PEREIRA, J.C.; ROCHA, F.C. et al. Avaliação da qualidade nutricional da silagem de cana-de-açúcar com aditivos microbianos e enriquecida com resíduos da colheita da soja. Revista Brasileira de Zootecnia, v.35, n.1, p.38-47, 2006.

JOBIM, C.C.; NUSSIO, L.G.; REIS, R.A. et al. Avanços metodológicos na avaliação da qualidade da forragem conservada. Revista Brasileira de Zootecnia, v.36, p.101-120, 2007 (supl. especial).

KLEINSCHMIT, D.H.; KUNG JÚNIOR, L. A meta-analysis of the effects of Lactobacillus buchneri on the fermentation and aerobic stability of corn and grass and small-grain silages. Journal of Dairy Science, v.89, p.4005-4013, 2006

KUNG JÚNIOR, L.; MUCK, R. Animal responses to silage additive. In: SILAGE: FIELD TO FEEDBUNK, 1997, Hershey. Proceedings... Hershey: NRAES-99, 1997. p.200-210.

KUNG JÚNIOR, L.; ROBINSON, J.R.; RANJIT, N.K. et al. Microbial populations, fermentation end-products, and aerobic stability of corn silage treated with ammonia or a propionic acid-based preservative. Journal of Dairy Science, v.83, p.1479-1486, 2000 . 
KUNG JÚNIOR, L.; STANLEY, R.W. Effect of stage of maturity on the nutritive value of whole-plant sugarcane preserved as silage. Journal of Animal Science, v.54, p.689-696, 1982.

McDONALD, P.; HENDERSON, A.R.; HERON, S.J.E. The biochemistry of silage. 2.ed. Merlow: Chalcomb Publications, 1991. 340p.

MOON, N.J. Inhibition of the growth of acid tolerant yeasts by acetate, lactate and propionate and their synergistic mixtures. Journal of Applied Bacteriology, v.55, p.453-460, 1983.

MUÑOZ-MALDONADO, J.G. Associação de aditivos químicos e microbianos no controle da fermentação e estabilidade aeróbia em silagens de cana-de-açúcar (Saccharum officinarum L.). 2007. 100f. Dissertação (Mestrado em Agronomia) - Escola Superior de Agricultura "Luiz de Queiroz", Universidade de São Paulo, Piracicaba.

QUEIROZ, O.C.M; SCHMIDT, P.; NUSSIO, L.G. et al. Estabilidade aeróbia de silagens de cana-de-açúcar confeccionadas com inoculantes bacterianos e aditivos químicos. In: REUNIÃO ANUAL DA SOCIEDADE BRASILEIRA DE ZOOTECNIA, 43., 2006, João Pessoa. Anais... João Pessoa: SBZ, 2006. (CD-ROM).

PEDROSO, A.F.; NUSSIO, L.G.; PAZIANI, S.F. et al. Dinâmica da fermentação e da microflora epífita em silagem de cana-deaçúcar. Scientia Agrícola, v.62, n.5, p.427-432, 2005.

PEDROSO, A.F.; NUSSIO, L.G.; LOURES, D.R.S. et al. Efeito do tratamento com aditivos químicos e inoculantes bacterianos nas perdas e na qualidade de silagens de cana-de-açúcar. Revista Brasileira de Zootecnia, v.36, n.3, p.558-564, 2007.

SANTOS, M.C.; NUSSIO, L.G.; MOURÃO, G.B. et al. Influência da utilização de aditivos químicos no perfil da fermentação, no valor nutritivo e nas perdas de silagens de cana-de-açúcar. Revista Brasileira de Zootecnia, v.37, n.9, p.1555-1563, 2008.

SCHMIDT, P. Improved efficiency of sugarcane ensiling for ruminant supplementation. In: INTERNATIONAL SYMPOSIUM ON
FORAGE QUALITY AND CONSERVATION, 2009, Piracicaba. Proceedings... Piracicaba: FEALQ, 2009. p.47-72.

SCHMIDT, P.; MARI, L.J.; NUSSIO, L.G. et al. Aditivos químicos e biológicos na ensilagem de cana-de-açúcar. 1. Composição química das silagens, ingestão, digestibilidade e comportamento ingestivo. Revista Brasileira de Zootecnia, v.36, n.5, p.1666-1675, 2007.

SIQUEIRA, G.R.; REIS, R.A.; SCHOCKEN-ITURRINO, R.P. et al. Perdas de silagens de cana-de-açúcar tratadas com aditivos químicos e bacterianos. Revista Brasileira de Zootecnia, v.36, n.6, p.2000-2009, 2007.

SILVA, D.J.; QUEIROZ, A.C. Análise de alimentos: métodos químicos e biológicos. 3.ed. Viçosa, MG: Editora UFV, 2002. 235p.

SOUSA, D.P.; MATTOS, W.R.S.; NUSSIO, L.G et al. Efeito de aditivo químico e inoculantes microbianos na fermentação e no controle da produção de álcool em silagens de cana-de-açúcar. Revista Brasileira de Zootecnia, v.37, n.9, p.1564-1572, 2008.

STATISTICAL ANALYSES SYSTEM - SAS. SAS user's guide: Statistics. Cary, 1996. 983p.

TOLEDO FILHO, S.G.; NUSSIO, L.G.; SCHMIDT, P. et al. Estabilidade aeróbia de rações contendo silagem de cana-deaçúcar inoculadas com Lactobacillus buchneri 40788 e de ingredientes concentrados. In: REUNIÃO ANUAL DA SOCIEDADE BRASILEIRA DE ZOOTECNIA, 41., 2004, Campo Grande Anais... Campo Grande: Sociedade Brasileira de Zootecnia, [2004]. (CD-ROM).

VALERIANO, A.R.; PINTO, J.C.; ÁVILA, C.L.S. et al. Efeito da adição de Lactobacillus sp. na ensilagem de cana-de-açúcar. Revista Brasileira de Zootecnia, v.38, n.6, p.1009-1017, 2009.

VAN SOEST, P.J.; ROBERTSON, J.B.; LEWIS, B.A. Methods for dietary fiber, neutral detergent fiber and nonstarch polysaccharides in relation to animal nutrition. Journal of Dairy Science, v.74, p.3583-3597, 1991. 